\title{
Análise da efetividade da política pública socioeducativa do Governo Federal nas regiões com vulnerabilidade social: 0 caso do Serviço de Convivência e Fortalecimento de Vínculos (SCFV) no município de ltaguaí (RJ)
}

Carlos Alberto Sarmento do Nascimento ${ }^{1}$ Lamounier Erthal Villela²

\section{Resumo}

Neste artigo apresenta-se como ocorre a atuação prática da política pública do Serviço de Convivência e Fortalecimento de Vínculos (SCFV) de responsabilidade do Ministério de Desenvolvimento Social e Combate à fome (MDS), em seis regiões urbanas, periurbanas e rurais existentes no município de Itaguaí (RJ), Brasil. Os resultados deste trabalho são consequência de uma avaliação de como ocorre, na dimensão social, a aplicabilidade dessa política pública específica, idealizada a partir de processos de dialogicidade e com uma concepção hierárquica em suas premissas, pautadas no aspecto social, questionando de quais formas essa política pública afeta o desenvolvimento local e o regional. Tal análise realiza uma comparação entre as teorias normativas indicadas pelo Governo Federal, tendo como perspectiva principal a visão e o papel dos atores locais (usuários - sociedade civil, profissionais do serviço e gestão pública local). Para uma melhor análise entre teoria e prática, foram utilizados os termos de gestão social, controle social e cidadania deliberativa como instrumentos elementares para a delimitação do que propõe a transposição da teoria para a prática, visto que esses termos têm como racionalidade o processo comunicativo e cooperativo entre Estado e sociedade civil, ou seja, este trabalho busca entender se o Serviço de Convivência e Fortalecimentos de Vínculos de fato proporciona, na prática, um desenvolvimento territorial para as localidades atendidas, na medida em que seu processo conceptivo de política pública perpassa obrigatoriamente por sua aplicabilidade em nível regional.

Palavras-chave: Políticas Públicas e Sociais. Desenvolvimento Local e Regional. Sociedade Civil. Gestão e Controle Social. Cidadania Deliberativa.

\footnotetext{
${ }^{1}$ Graduação em Ciências Sociais. Mestre em Desenvolvimento Territorial e Políticas Públicas (PPGDT/UFRRJ). ca.sarmento@ig.com.br

2 Pós-doutor em Administração Pública (EBAPE/FGV). Doutor em Economia Aplicada (Université Paris III). Professor do Programa de Pós-Graduação em Desenvolvimento Territorial e Políticas Públicas - PPGDT e do Doutorado em Ciência, Tecnologia e Inovação em Agropecuária (PPGCTIA-UFRRJ). lamounier.erthal@gmail.com
} 


\begin{abstract}
This article proposes to present as is the practical application of public policy Serviço de Convivência e Fortalecimento de Vínculos (SCFV) of the Ministry of Social Development and Fight against Hunger (MDS) responsibility in six territories of urban areas, peri-urban and rural existing in municipality of Itaguai (RJ), Brazil. The results of this work pervade to conduct an assessment of how is the practical applicability of the social dimension of this particular public policy conceived from dialogical process and a hierarchical design of its premises guided the social aspect, questioning to which this public policy forms affects regional and local development. Realizing this comparative analysis between the normative theories indicated by the Federal Government, the main perspective the vision and the role of local actors (users - civil society, professional service and local public administration). For a better analysis of theory and practice were used the terms social management, social control and deliberative citizenship as basic tools for delineation of proposing the implementation of theory to practice, as these terms have as rationality the communicative and cooperative process between State and civil society, ie this work seeks to understand the Coexistence Service and fact Linkages fortifyings provides in practice territorial development to the locations served, in that their conceptional process of public policy must permeates its practical applicability at the regional level.
\end{abstract}

Keywords: Public Policies and Social. Local and Regional Development. Civil Society. Management and Social Control. Deliberative Citizenship.

\title{
1 Introdução
}

O objetivo deste artigo é analisar o Serviço de Convivências e Fortalecimento de Vínculos (SCFV), no município de Itaguaí, Estado do Rio de Janeiro (RJ), Brasil, como um processo que, de fato, possa conduzir a um desenvolvimento regional, avaliando-o, como processo de análise, sob as óticas da gestão social ${ }^{3}$, controle social ${ }^{4} \mathrm{e}$ cidadania deliberativa ${ }^{5}$.

O SCFV é uma política pública do Governo Federal que tem suas ações realizadas de forma continuada em regiões específicas no território brasileiro, principalmente em localidades mais afastadas dos centros urbanos ou com camadas da população desprivilegiadas socioeconomicamente (MDS, 2007b), realizando ações e atividades de forma conjunta, principalmente com parcelas da população que padecem de situações como violência, negligência, isolamento e pobreza.

Sua responsabilidade é do Ministério de Desenvolvimento Social e Combate à Fome (MDS), sua atuação ocorre diretamente nos municípios, através das Secreta-

\footnotetext{
${ }^{3}$ Construção coletiva a partir da dialogicidade e emancipação dos entes (Estado, Sociedade civil e Mercado).

${ }^{4}$ Mecanismo individual ou coletivo de Entidades (conselhos) que visam uma fiscalização contínua de instâncias públicas.

5 Pluralidade Participativa das instâncias da sociedade civil, baseada na inexistência de privilégios.
} 
rias Municipais de Assistência Social (SMAS), e sua aplicação acontece nas unidades do Centro de Referência da Assistência Social (CRAS), distribuídas pelos territórios dos municípios atendidos, com a função de estabelecer uma proximidade física nas localidades que mais necessitam das ações afirmativas do Estado (BRASIL, 2010).

Essas propostas baseiam-se em atividades socioeducativas de relações interpessoais e têm o intuído de ampliar o acesso à informação dos usuários a partir de ações afirmativas, relacionadas à sua permanência na escola, acesso ao esporte, cultura, lazer, vida saudável, etc. Sua finalidade é promover e estimular a sociedade civil a ocupar seus espaços de direito nos equipamentos e entidades que visam a uma fiscalização contínua de instâncias públicas, buscando, assim, a promoção e o desenvolvimento das regiões atendidas.

A problemática desta pesquisa consiste em compreender, sob a ótica de gestão e controle social e de cidadania deliberativa, como ocorre a atuação do Serviço de Convivência e Fortalecimento de Vínculos (SCFV) no município de Itaguaí (RJ), com base no processo dialógico entre sociedade civil, Estado e políticas públicas e sua aplicação nos territórios atendidos.

\subsection{Itaguaí}

Localizado na região metropolitana do Rio de Janeiro (RMRJ), o município de Itaguaí está a aproximadamente $72 \mathrm{Km}$ da capital, tem uma área total de 275, $870 \mathrm{~km}^{2}$, com uma densidade populacional de 402,98 hab. $/ \mathrm{km}^{2}$, cujas faixas etárias predominantes encontram-se entre 10-14, 25-29 e 30-34 anos. Dessa população, 96,31\% mora em área urbana, enquanto 3,69\% vive em área rural, segundo o Instituto Brasileiro de Geografia e Estatística (IBGE, 2013).

Atualmente, o município é dividido em 44 bairros e uma zona de preservação ambiental, segundo a Lei Municipal $n^{\circ}$ 3.204, de 23 de dezembro de 2013, que estabelece o abairramento do município de Itaguaí (ITAGUAÍ, 2014).

\section{Tabela 1 - Aumento populacional por período - Itaguaí}

\begin{tabular}{|c|c|c|}
\hline Ano & Número total de habitantes & Aumento por período (\%) \\
\hline 1970 & $23.309 \mathrm{mil}$ & $\mathrm{x}$ \\
\hline 2000 & $82.030 \mathrm{mil}$ & $251.924 \%$ \\
\hline 2007 & $95.356 \mathrm{mil}$ & $16.245 \%$ \\
\hline 2010 & $109.091 \mathrm{mil}$ & $14.403 \%$ \\
\hline 2014 & $117.347 \mathrm{mil}$ & $7.567 \%$ \\
\hline
\end{tabular}

Fonte: Elaborado pelo autor com base em dados da Fundrem (1981) e IBGE 2000-2010 (2013).

Com base nos dados do IBGE (2013), o município de Itaguaí tem atualmente uma população estimada de 117.347 mil habitantes, indicando um aumento expressivo de 43.053\% de sua população no período 2000 - 2014. 


\subsection{Objetivo}

O objetivo central é analisar a política pública do SCFV/MDS, comparado a sua concepção teórica (metodologia, orientação técnica, instrumentos de gestão e seu legislativo) com a prática (realidade) do serviço, nas seis unidades do Centro de Referência da Assistência Social (CRAS) no município de Itaguaí (RJ). Durante o processo de análise, serão utilizadas as óticas do controle e gestão social e cidadania deliberativa.

\section{Pesquisa de campo}

Com base na descrição de aspectos metodológicos de Vergara (2007), a pesquisa de campo foi realizada com os atores sociais e institucionais locais, com a finalidade de desenvolver um "[...] processo de interação social entre duas pessoas na qual uma delas, o entrevistador, tem por objetivo a obtenção de informações por parte do outro, o entrevistado" (HAGUETTE,1997, p. 86).

O modelo de entrevista empregado utilizou o padrão de questões semiestruturadas (VERGARA, 2007), onde o entrevistado teve a oportunidade de discorrer sobre as questões propostas, assim como a oportunidade de abordar de forma mais profunda algum tema de seu interesse relacionado à pesquisa.

Foi utilizada a proposta de saturação das respostas, onde ocorre uma similaridade ou repetição nas informações dos entrevistados, "[...] onde a saturação designa o momento em que o acréscimo de dados e informações em uma pesquisa não altera a compreensão do fenômeno estudado." (THIRY-CHERQUES, 2009, p. 49).

Respeitando a sugestão do ponto de saturação de Guest, Bunce e Johnson (2006), ocorreram quatorze entrevistas com os usuários dos SCFV, em cada uma das seis unidades de atendimento do CRAS, local onde é oferecido o SCFV, perfazendo um total de 84 usuários entrevistados.

Tabela 2 - Universo de Amostragem

\begin{tabular}{|l|c|c|}
\hline \multicolumn{1}{|c|}{ Entrevistados } & Número por unidade do CRAS (x 6) & Total \\
\hline Usuários & 14 & 84 \\
\hline Profissionais Pedagógicos & 3 & 18 \\
\hline Diretor(a) de Planejamento & $* *$ & 1 \\
\hline Diretor(a) da Unidade Básica & $* *$ & 1 \\
\hline & & 104 \\
\hline
\end{tabular}

Fonte: Elaboração dos autores.

Também foram entrevistados três profissionais pedagógicos por unidade, nos seis equipamentos do CRAS onde ocorrem as atividades do SCFV, totalizando dezoito profissionais da equipe pedagógica, além da diretora de planejamento e da diretora da unidade básica de atendimento. 


\section{A política pública do Serviço de Convivência e Fortalecimento de Vínculos (SCFV)}

O Serviço de Convivência e Fortalecimento de Vínculos (SCFV) é uma proposta de políticas públicas do governo federal sob a responsabilidade do Ministério de Desenvolvimento Social e Combate à Fome (MDS), desenvolvido em caráter nacional, com execução prática nas unidades municipais de atendimento do Centro de Referência da Assistência Social (CRAS).

Sua origem é a Medida Provisória no 238, de 2005, e a Lei no 11.129, de 2005, ratificada na Lei $\mathrm{n}$ - 11.692, de 2008, ainda com a nomenclatura de "Projovem Adolescente", atendendo exclusivamente jovens entre 14 e 18 anos, porém, no ano de 2013, o MDS identifica a necessidade de ampliação do serviço.

Dessa forma, em outubro de 2013, é oficialmente criado pelo governo federal o Serviço de Convivência e Fortalecimento de Vínculos (SCFV) que agrega beneficiados entre 6 e 13 anos e com mais de 60 anos, além da faixa etária entre 14 e 18 anos, que já fazia parte do então extinto "Projovem Adolescente".

A Unificação das regras para a oferta qualificada do SCFV, que visa equalizar/uniformizar a oferta, unificar a lógica de cofinanciamento federal, possibilitar o planejamento da oferta de acordo com a demanda local, garantir serviços continuados, potencializar a inclusão dos usuários identificados nas situações prioritárias e facilitar a execução do SCFV, otimizando os recursos humanos, materiais e financeiros (MDS, 2013a, p. 1).

Segundo o livro "Concepção de convivência e fortalecimento de Vínculos" (MDS, 2013a) e a Cartilha do Reordenamento (MDS, 2013b), mesmo com a mudança estrutural de financiamento do serviço, a proposta metodológica das atividades permaneceria inalterada, desenvolvida a partir de um conteúdo programático, que seria previamente arquitetado a partir das diretrizes do MDS em comunhão com o território em que seria desenvolvido o serviço, tendo a finalidade de desenvolver ações coletivas de interesse social, através de um planejamento participativo proposto pelos usuários dos serviços, construindo ações e projetos concretos.

Os conceitos servem para entender o trabalho e também para fazer funcionar a ação [...] Uma situação em que o trabalho social se caracteriza pela definição de tema comum a todos os usuários (esporte, cultura, lazer, artesanato, reciclagem) com abordagem e estilo pessoal (de quem faz), orientado por processos de formação [...]. O tema é identificado no contexto com o usuário, a abordagem tem uma referência teórico-metodológica e o estilo é orientado por uma [...] produção coletiva de uma equipe. A finalidade é o engajamento do usuário na gestão dos serviços como experiência de construção conjunta (MDS, 2013a, p. 13-14).

Tal planejamento, portanto, seria construído a partir da participação da sociedade local, de uma forma dialógica, que priorizasse as particularidades sócio-históricas e culturais onde o serviço está inserido, respeitando a subjetividades do local.

Sobre a proposta educativa e metodológica do SCFV e a implementação dos Serviços de Convivência e Fortalecimento de Vínculos no Município de Itaguaí (RJ): atualmente, o SCFV é teoricamente caracterizado com base em práticas educativas 
que priorizam um "[...] universo cultural e histórico e um conjunto de relações e inter -relações a serem considerados, bem como situações a ser objeto da ação articulada das diversas políticas públicas" (MDS, 2013a).

Segundo o livro Traçado Metodológico (2009), as atividades pedagógicas do SCFV são desenvolvidas adotando as seguintes propostas ${ }^{6}$ (BRASIL, 2009, p. 15):

1. Ampliar o acesso e a permanência do usuário na escola de qualidade (para as faixas etárias de crianças e adolescentes);

2. Erradicar o analfabetismo;

3. Preparar para o mundo do trabalho;

4. Gerar trabalho e renda;

5. Promover vida saudável;

6. Democratizar o acesso dos usuários ao esporte, ao lazer, à cultura e à tecnologia da informação;

7. Promover os direitos humanos e as políticas afirmativas;

8. Estimular a cidadania e a participação social dos usuários, e

9. Melhorar a qualidade de vida dos usuários nos meios urbano, rural e nas comunidades de referência.

As propostas de atuação/ação, segundo o MDS (2007a; 2013a: 2013b; 2014) e Brasil (2009; 1993), são desenvolvidas a partir de atividades específicas, como reuniões entre usuários e técnicos da unidades; planos de debate para resolução de problemas locais; promoção e desenvolvimento das características regionais, a partir do desenvolvimento de feiras culturais; torneios esportivos; atividades inter-relacionais; feiras literárias; saraus musicais; rodas de leitura; feiras vocacionais; feira de exposição de artesanato; planos locais de atuação, etc.

Além dessas, as atividades específicas e regulares, como prática esportiva, dança, capoeira, informática, música, artesanato, literatura, culinária, orientação social, atividades do mundo do trabalho, etc., buscando como resultado final a "[...] socialização e desenvolvimento de valores e habilidades para [...] a vida em sociedade" (BRASIL, 2009, p. 27), utilizando para isto eixos estruturantes que integram as propostas de convivência social, mundo do trabalho e participação cidadã.

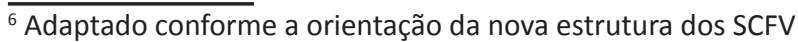


Figura 1 - Eixos estruturantes SCFV

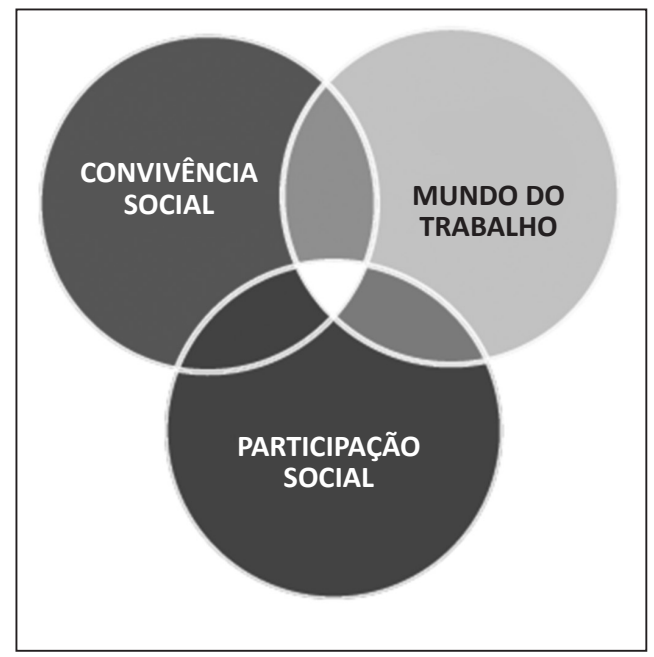

Fonte: Brasil (2009).

Teoricamente, as propostas das dimensões metodológicas dos SCFV acompanham uma indicação "freiriana" de educação, que prioriza a dialogicidade entre seus pares como prática da liberdade, e que proporciona aos usuários do SCFV um conhecimento intrínseco sobre os temas de controle social e de cidadania deliberativa.

O diálogo é este encontro dos homens, imediatizados pelo mundo, para pronunciá-lo, não se esgotando, portanto, na relação eu-tu. Esta é a razão por que não é possível o diálogo entre os que querem a pronúncia do mundo e os que não querem; entre os que negam aos demais o direito de dizer a palavra e os que se acham negados deste direito (FREIRE, 2005, p. 91)

As ações de busca da ascensão regional de seus atores têm como base as dimensões (BRASIL, 2009):

1. Dialógica,

2. Reflexiva,

3. Cognitiva,

4. Afetiva,

5. Ética,

6. Estética,

7. Lúdica. 
Figura 2 - Eixos estruturantes SCFV

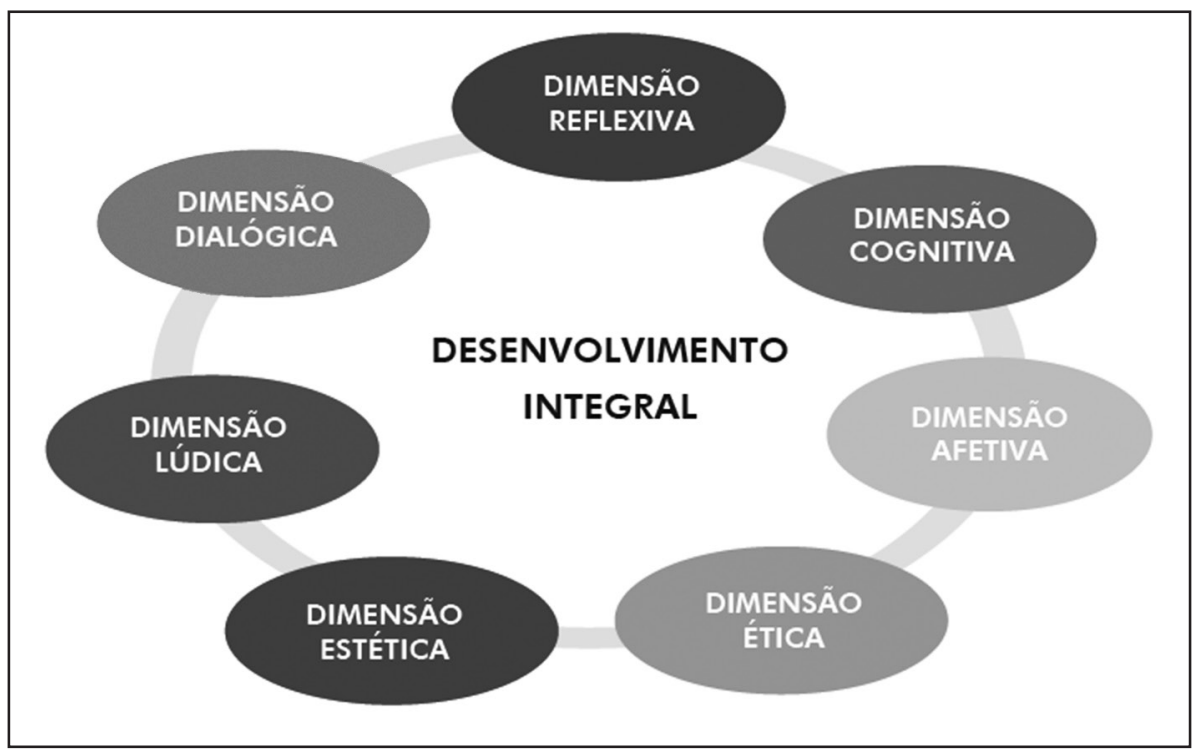

Fonte: Brasil (2009).

A implementação do SCFV, no município de Itaguaí, ainda com a nomenclatura de Projovem Adolescente, iniciou no ano de 2009, em caráter experimental, na unidade do Centro de Referência da Assistência Social (CRAS) visando à capilarização das ações em regiões mais pobres, buscando a aproximação da população assistida com a política pública.

Territorialização: o serviço deve ser ofertado próximo à moradia dos jovens e suas famílias, no território de abrangência do CRAS. Define-se aí um universo cultural e histórico e um conjunto de relações e inter-relações a serem considerados, bem como situações a serem objeto da ação articulada das diversas políticas públicas (BRASIL, 2009, p. 7).

Atualmente, no município de Itaguaí, existem ao todo seis unidades do CRAS que têm a função inicial de subdividir os bairros do município entre essas unidades por proximidade e características territoriais comuns em um raio geográfico total de $21 \mathrm{~km}$ entre elas.

O Centro de Referência é um espaço físico onde funciona um serviço municipal de atendimento psicossocial às famílias vulneráveis em função de pobreza e de outros fatores de risco e exclusão social. Têm como base territorial comunidades, regiões, bairros onde há maior concentração de famílias nessas condições (MDS, 2007b, p. 7).

O capítulo a seguir busca um entendimento de como se dá, na prática, esse processo de execução e avaliação das políticas pública e social dos SCFV em Itaguaí, além de buscar elucidar como ocorre a execução dessa política pública no âmbito regional, a partir das instâncias de gestão e controle social e cidadania deliberativa. 


\section{Instâncias de gestão social, controle social e cidadania deliberativa e o SCFV no município de Itaguaí}

A proposta deste capítulo é traçar um panorama entre a atividade prática do SCFV no município de Itaguaí com os termos de gestão social, controle social e cidadania deliberativa. Esses termos têm em sua essência a atuação de instâncias da sociedade civil num processo de construção cidadã que tenha como resultado o bem comum (TENÓRIO, 2012). Para a construção dessa análise, serão utilizados trechos das falas captadas durante as entrevistas realizadas com usuários da política pública do SCFV no município em questão.

Tratar sobre os três termos acima citados é abordar a atuação direta da sociedade civil nos processos de fiscalização, vigilância e respeito, principalmente nos de políticas públicas (SIRAQUE, 2009), e, como está proposta, pode afetar diretamente as ações promotoras do desenvolvimento regional das localidades atendidas. Nesse sentido, o próprio MDS indica metodologicamente que a construção dos SCFV deva ser pautada em uma ideologia pluralista da participação da sociedade civil na medida em que:

Deve ser sempre um processo coletivo, envolvendo todos os atores e segmentos interessados que, trazendo conhecimentos especializados, práticas diferenciadas, diferentes leituras da realidade, constroem tendências e interesses, aliançando decisões, pactuando prioridades na definição de objetivos, metas, procedimentos e resultados a alcançar (MDS, 2007b, p. 32).

Portanto, sendo o sujeito (sociedade civil/usuário do serviço) o agente primordial de construção, execução e análise de políticas públicas e sociais, esse processo parte dele e é ele o maior beneficiado (MDS, 2014). Assim sendo, analisar as políticas públicas do SCFV pelo viés dos termos propostos oferece um entendimento do serviço em nível de dimensão social7.

Teoricamente, as políticas públicas direcionadas pelo MDS são definidas a partir de sua tipificação nacional, tendo no usuário do território o principal personagem desse processo de construção das atividades do serviço, proporcionando a atuação desse indivíduo de forma a promover a "[...] constituição de espaços de convivência, formação para a participação e cidadania [...] a partir de interesses, demandas e potencialidades" (MDS, 2014, p. 9), com uma proposta endógena do espaço de atuação. Ou seja, a política pública deve ser constituída de uma forma ampla e coletiva entre todas as instâncias de controle social, tendo o usuário do serviço (sociedade civil) como principal beneficiário desse processo, desenvolvendo as atividades de uma forma coletiva com o Estado e o mercado (CANÇADO, 2013).

Entretanto, o panorama apresentado nas entrevistas, nas seis unidades do CRAS onde o SCFV é oferecido, revela uma realidade distinta da teoria proposta pelas diretrizes do MDS, já que, por mais que "[...] o território ofereça a demanda, o

\footnotetext{
7 A dimensão social trata sobre o processo de descentralização de políticas públicas no sentido estratégico do apoderamento de grupos sociais, expressando a vontade coletiva da sociedade civil de um determinado território, exercendo funções fiscalizadoras e de controle sobre serviços públicos (RUA; ROMANINI, 2014b).
} 
serviço não está preparado para a realização da mesma" (PROFISSIONAL PEDAGÓGICO - CRAS), na medida em que os usuários do serviço não percebem um processo heterárquico e horizontal na concepção dessa política pública em suas respectivas unidades, não promovendo seu contínuo desenvolvimento regional.

Não, eles [gestores públicos] não se preocuparam com isso (dialogar com o usuário) ao longo do ano [...] Não foi feita nenhuma pesquisa, entrevista, reunião, para pegar nossas opiniões, sobre como deveriam ser as atividades ou como poderíamos contribuir no dia a dia do serviço (USUÁRIO DAS UNIDADES DO CRAS, 2015).

O usuário, integrante da sociedade civil, não sendo convidado a fazer parte ativa da construção dessa política pública, acaba, por consequência, não atuando como agente de mudanças na instância local

O cenário que se apresenta, referente ao SCFV no município de Itaguaí, é de um mercado local que acaba ditando o ritmo das ações como o ideal das ações e interesses da população, formando sujeitos altamente tecnicistas e desumanizados (LISBOA, 2009), tendo o Estado um papel de conivência, não proporcionando atividades socioeducativas de uma forma cooperativa e heterárquica aos usuários do território, as quais visem à valorização dos aspectos endógenos de sua região.

A realidade observada com relação às atividades do SCFV aproxima-se da concepção de uma racionalidade instrumental (RAMOS, 1989) no sentido de se buscar resultados técnicos, de caráter econômico, onde o que importa são os resultados e não os meios. Sendo assim, as atividades oferecidas pelo SCFV apresentam extensões das necessidades instrumentais e monológicas do mercado formal, moldando um "cidadão burocratizado" (WEBER, 1979), contribuindo na constituição de uma sociedade que tenha suas ações direcionadas "[...] para a utilização de um tipo de ação reacional dirigida ao campo industrial, ou material, mas, também, à esfera das relações humanas e à dominação burocrática [...] limitando apenas ao campo da produção e do consumo" (LISBOA, 2009, p. 13), oferecendo uma proposta de política pública não dialógica com a sociedade civil, perpetrando, na prática, um Estado que se torna um modelo de mercado capitalista através de uma dominação burocrática (CANÇADO; PEREIRA; TENÓRIO, 2013), na medida em que a participação social fica meramente no aspecto teórico, e as tomadas de decisão se aplicam nos relatórios técnicos e não na dialogicidade entre os indivíduos e na intersubjetividade das características do território.

A gestão social não obedece ao padrão de gestão estratégica, pois busca substituir a gestão burocrática e monológica, por um gerenciamento participativo, dialógico em que o poder de decisão é deliberado pelos vários atores sociais envolvidos. Neste estudo, a gestão social é pensada de acordo com o modelo de democracia deliberativa de Habermas, na medida em que o alicerce de seu processo de tomada de decisão pressupõe a participação de todos os atores sociais que direta ou indiretamente tenham relações com o tema em debate (MACEDO, 2014, p. 139).

Neste sentido, a política pública do SCFV aparenta um distanciamento de sua aplicabilidade como mecanismo de desenvolvimento regional a partir dos anseios 
da sociedade civil local. Aproxima-se da atuação da esfera privada por meio de uma gestão estratégica onde o que é oferecido tem uma característica top down ${ }^{8}$, voltada somente para o mundo do trabalho, linear, objetivo e não dialógico, com uma ideologia de racionalidade funcional (MANNHEIM, 1973), que visa ao determinismo humano, não se preocupando com os meios que conduzem o processo, e sim com um resultado com critérios funcionais específicos.

Teoricamente, as atividades socioeducativas do SCFV deveriam ter esse papel na formação de indivíduos atuantes, "[...] estimulando a participação na vida pública do território e desenvolvendo competências para a compreensão crítica da realidade social e do mundo contemporâneo" (BRASIL, 2010, p. 44).

O processo de formulação e gestão de políticas públicas [...] um movimento dinâmico e complexo, que envolve estruturas e sujeitos que interagem e trazem diferentes [...] funções de articulação, planejamento, coordenação, negociação, monitoramento e avaliação das ações desenvolvidas, em sintonia com as instâncias federativas que integram o sistema de operação e de controle social (MDS, 2007a, p. 12-13).

Assim, uma das principais propostas do SCFV seria a de uma ação formuladora de agentes de mudanças regionais nas instâncias de fiscalização de suas localidades, estimulando a "[...] participação da sociedade civil no processo de concepção e gestão das políticas públicas, em especial as classes menos favorecidas e dos setores identificados com as demandas populares" (MDS, 2007b, p. 15).

Para tanto, utilizaria o próprio local como um processo descentralizador da política pública, feita no território em seu benefício próprio, desenvolvendo uma proposta de dimensão social, cujos maiores beneficiados seriam teoricamente os moradores das próprias localidades atingidas pelo serviço.

Trata-se da dimensão social, segundo a qual a descentralização é concebida como uma estratégia de capacitação de grupos sociais para decidirem sobre problemas de gestão pública local, seja estruturando formas institucionais capazes de expressar a vontade coletiva nas instâncias de tomada de decisão, ou como forma de possibilitar à população exercer diretamente funções de fiscalização e controle sobre a gestão de serviços públicos (RUA; ROMANINI, 2014b, p. 10).

Contudo, outra realidade é apresentada, na medida em que não existe formação direta ou indireta para agentes locais, para atuarem nas instâncias de controle social em suas localidades.

Não temos conhecimento dessas atividades, que não são divulgadas [...] não fomos apresentados a esses espaços, não sabemos se eles existem $e$ como podemos fazer para integrá-los (USUÁRIOS - CRAS).

Não existem conselhos comunitários no território [...] existe somente no papel, isso não é posto em prática aqui no local onde moramos (USUÁRIOS - CRAS).

\footnotetext{
${ }^{8}$ Sistema simplista e sistemático de implementação de uma política feita de forma verticalizada, de cima para baixo, onde nem todos os integrantes são ouvidos (SILVA; MELO, 2000).
} 
Entretanto, segundo Macedo (2014), existem conselhos ativos que realizam reuniões periódicas, em cinco dos seis territórios atendidos pelo SCFV no município de Itaguaí (exceto território do CRAS Engenho), totalizando vinte Conselhos Comunitários ${ }^{9}$, os quais são:

1. CRAS BRISAMAR: Conselhos Comunitários do Brisamar, Ilha da Madeira e Coroa Grande.

2. CRAS CALIFÓRNIA: Conselhos Comunitários Ibirapitanga, Parque Primavera e Piranema.

3. CRAS CENTRO: Conselhos Comunitários do Centro e Santa Cândida.

4. CRAS MAZOMBA: Conselho Comunitário do Mazombinha.

\section{Mapa 1 - Conselhos Comunitários no Município de Itaguaí (RJ)}

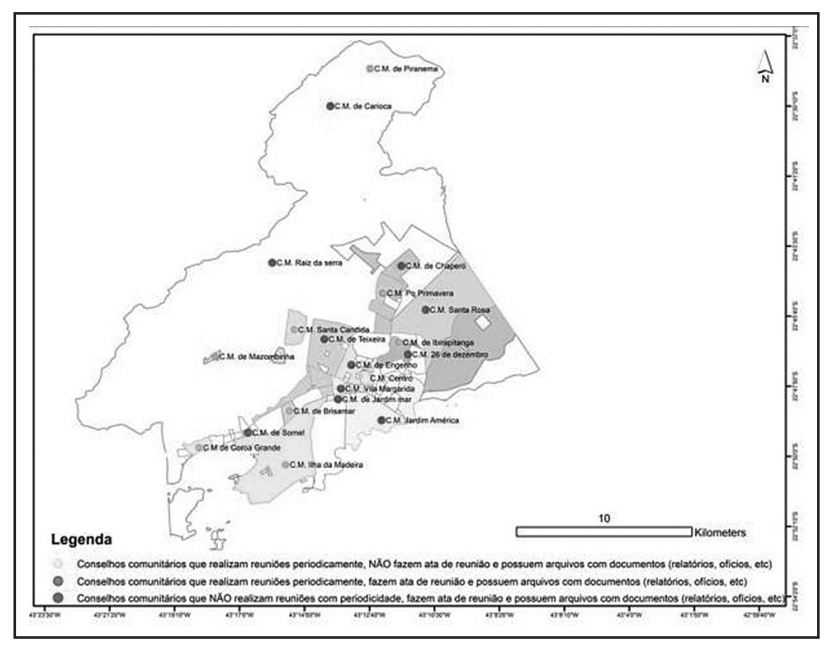

Fonte: Macedo (2013).

Desta forma, pode-se afirmar que todos os territórios abrangidos pelas unidades do CRAS têm, em suas localidades, a ocorrência de instâncias ativas de controle social. Entretanto, como foi apontado nos relatos dos entrevistados, boa parte dos usuários e da sociedade civil não participa/desconhece essas instâncias de controle social, e/ou não foi instigada a participar ativamente nesses espaços públicos, na medida da formação de agentes de fiscalização e desenvolvimento regional a partir da política pública do SCFV.

A tipificação nacional determina que o CRAS deva "[...] assegurar espaços de referência para o convívio grupal, comunitário e social [...] bem como estimular o desenvolvimento de potencialidades, habilidades, talentos e propiciar sua formação cidadã" (BRASIL, 2010, p. 43-44) através de seus serviços.

\footnotetext{
${ }^{9}$ Entre ativos e inativos.
} 
Ou seja, as ações práticas do SCFV deveriam ser pautadas em uma proposta de racionalidade subjetiva (RAMOS, 1989), com o intuito de promover o potencial humano, por meio de um processo construído de forma coletiva, priorizando as contribuições dos usuários, do território e dos profissionais diretamente envolvidos.

A racionalidade substantiva, em primeiro lugar, nunca poderá ser confinada num enunciado interpretativo, somente através da livre experiência da realidade e de sua precisa articulação poderá ser compreendida, não se pode compreendê-la através da simples aquisição de um pacote de informações (RAMOS, 1989, p. 194).

Neste sentido, o SCFV, no município de Itaguaí, apresenta falhas no que se refere à promoção de seus usuários como integrantes de instâncias de controle social que resulte em uma melhoria nas ações do Estado em níveis locais e municipais. É o que Souza (2005) trata como uma participação secundarizada, sem efetividade, construída de forma prática e distinta de sua concepção, realizada em um sentido burocrático, diferente do que é previamente estabelecido na Constituição Federal de 1988, que trata dos instrumentos de gestão como alternativa da participação popular nas instâncias públicas.

As dificuldades entre teoria e prática, no que se refere aos termos de gestão e controle social e o SCFV no município de Itaguaí, afetam diretamente a cidadania deliberativa, que tem sua acepção pautada na prerrogativa da tomada de decisões públicas e no processo dialógico, voltados para o pluralismo e igualdade participativa, visando ao bem comum (TENÓRIO, 2013).

Na definição do MDS, a cidadania participativa deve ser constituída coletivamente com a localidade na qual a política pública está inserida numa proposta circular de trocas constantes de informações, ações e decisões conjuntas entre o Estado e os usuários de suas políticas públicas (BRASIL, 2009a). Assim, "[...] a sociedade civil seria cooperativa, parceira: não um campo de lutas ou oposições, mas um espaço de colaboração e de ação construtiva" (NOGUEIRA, 2004, p. 59).

A igualdade participativa seria o diferencial entre outras políticas territoriais, na medida em que a própria sociedade beneficiada seria a principal promotora de seu desenvolvimento regional no que tange aos aspectos de fiscalização das instâncias públicas e promoção de suas características socioculturais. Entretanto, na prática, o relatado foi que "A burocratização do serviço impede em vários sentidos a participação interativa com a comunidade" (PROFISSIONAL EQUIPE PEDAGÓGICA CRAS).

Assim sendo, as propostas de cidadania deliberativa indicadas teoricamente pelo MDS sofrem alterações, quando chegam ao nível prático, distanciando-se de sua indicação teórica, que sugere o pluralismo de participações. Ou seja, a "[...] política se torna, portanto, objeto da administração, despolitizando-se [...] como a neutralidade técnica e política dos seus métodos de tomada de decisões" (LISBOA, 2009, p. 15). 
Na verdade, a participação do usuário é exceção, em grande parte, as atividades que realizamos são enlatadas, estão muito mais preocupados em manter a pessoa obediente, parecendo uma empresa, e pouco se aborda o pensamento crítico das pessoas que participam das atividades (PROFISSIONAL EQUIPE PEDAGÓGICA - CRAS)

O distanciamento do diálogo e da participação cidadã acaba, intrinsecamente, deixando as políticas públicas como agentes de simples realizações de "serviços" para a sociedade, não propondo uma atuação participativa e seu desenvolvimento regional. O resultado dessas ações resulta em um "Estado como aparato de dominação e não como campo de disputas e construção de consensos, no qual a correlação de forças tem papel decisivo para o encontro de soluções positivas" (MDS, 2007b, p. 15). Esse perfil de política pública monológica acaba, por fim, construindo uma sociedade distante do debate.

Ao mesmo tempo em que amplia a aplicação de razão instrumental na gestão da sociedade, o Estado e a sociedade renunciam progressivamente ao debate público sobre os fins e as metas da vida social, e, portanto, sobre aquilo que deveria nortear as políticas públicas. Os problemas e as soluções [...] transformam-se em questões técnicas e por isso suas definições passam a ser atribuídas a especialistas (LISBOA, 2009, p. 15).

As dificuldades de transposição das diretrizes técnicas e metodológicas do SCFV indicadas pelo MDS, para a sua prática nos seis territórios do município de Itaguaí, resultam em uma política pública com pouca efetividade e dificuldade de aproximação da sociedade civil em seus territórios, não promovendo nem desenvolvendo efetivamente a região.

O que fica claro é a construção de um planejamento desconhecedor das realidades do território, onde os participantes da sociedade civil operam de forma meramente decorativa (COSTA, 2000), onde as ações da política pública "[...] representam apenas um amontoado de intenções sobre a solução de um problema [...]. Nada disso garante que a decisão se transforme em ação" (RUA; ROMANINI, 2014a, p. 3).

Ou seja, não é possível afirmar a efetivação do que é proposto pela política pública do SCFV - MDS, enquanto as instâncias da gestão municipal não estiverem atentas às características endógenas dos territórios atendidos e não proporcionarem a abertura do diálogo com as comunidades locais, que promovam, na prática, seu desenvolvimento regional.

\section{Considerações finais}

Pode-se concluir que a política pública do serviço de convivência e fortalecimento de vínculos tenta, teoricamente, uma aproximação com as diversidades culturais, econômicas, étnicas, históricas e ambientais existentes nos territórios atendidos, visando ao desenvolvimento local e regional dos territórios atendidos, entretanto isso não garante a certeza da aplicação dessas premissas teóricas na prática.

Foi averiguada, durante a pesquisa, uma série de dificuldades de transição entre a concepção teórica e a prática em todas as unidades atendidas por essa políti- 
ca pública no município de Itaguaí (RJ). As dificuldades na formação de um processo dialógico mostraram-se recorrentes entre os entrevistados, sendo um dos principais problemas apontados pelos usuários e profissionais do serviço.

Esses entraves relacionados às dificuldades de participação da sociedade civil na construção coletiva do SCFV apresentam um panorama de racionalidade instrumental e monológica no cotidiano da política pública, situação rotineira no mundo empresarial, aparentando uma espécie de doutrinamento do pensamento da população local, inclusive com relação ao seu papel junto às políticas públicas e sociais.

Teoricamente, essas atividades deveriam conduzir os usuários a saírem do estágio de inércia com relação à participação em instâncias de controle social nos conselhos locais existentes, com previsão de transformá-los em agentes de promoção e fiscalização do desenvolvimento regional

Ficou comprovado ainda o desconhecimento das propostas da política pública dos SCFV por parte das equipes pedagógicas locais, devido à falta de um preparo e capacitação prévia. A não formação específica desses profissionais, para a leitura de questões indicadas pelos traçados metodológicos do serviço, associada à falta de boas condições de trabalho, à escassez de materiais e de espaços físicos inadequados, resultou em um distanciamento entre o que é proposto e definido como prioridade teórica pelo MDS e o que ocorre na prática nas instâncias do SCFV no município de Itaguaí.

Foi identificada uma fragilidade entre as perspectivas do que seria um processo de desenvolvimento entre sociedade civil, profissionais pedagógicos e as coordenações locais e municipais, o que resulta na fragilidade da relação entre esses atores acarretando a não aplicação prática das características históricas e culturais endógenas das comunidades atendidas pelo SCFV, diferentemente do que é indicado nas normativas metodológicas do MDS.

As falhas no processo dialógico entre as coordenações e os territórios atendidos resultam em uma falha na aplicabilidade da gestão social, do controle social e da cidadania deliberativa, e, consequentemente, numa não aplicabilidade das propostas de promoção do desenvolvimento regional a partir das características sócio-históricas e culturais locais.

Como aspecto positivo, foi percebido o intuito de propor o serviço de uma forma digna e minimamente confortável para os usuários participantes, mesmo mediante as dificuldades, como a falta de capacitação destas equipes e a ausência de boas condições de trabalho.

Fica nítida a necessidade de monitoramente (em nível das instâncias municipais), visando a melhores condições de trabalho, que propiciem a execução de um serviço pautado em uma emancipação do indivíduo, para que esses membros atendidos sejam novos entes formadores de opinião e integrantes ativos das esferas de controle e fiscalização dos bens e serviços públicos.

É necessário que as políticas públicas, como o SCFV, sejam um processo que desenvolva uma parceria com a sociedade civil e respeite suas características endógenas, ao invés das diretrizes impostas pelo mercado, arquitetando uma sociedade atuante nas ações da esfera pública, oferecendo uma política pública que tenha 
como benefício uma melhoria na qualidade de vida dos territórios e da sociedade civil local.

Contudo, esta pesquisa conclui que, mesmo com as dificuldades diagnosticadas, a política pública do SCFV, no município de Itaguaí, é de fundamental importância para as localidades atendidas, devido ser uma das poucas alternativas de atividades que, mesmo de forma precária, promove um desenvolvimento regional voltado para as comunidades mais pobres. O continuísmo desse serviço se faz essencial, principalmente para os usuários que se encontram em estado de vulnerabilidade social, pois muitos veem nesta política pública a única alternativa de atividade em seus respectivos territórios. Encerrar as atividades do SCFV é intensificar a ausência do Estado em territórios pobres e carentes, propiciando o controle dessas localidades por poderes paralelos, como a milícia e o tráfico de drogas.

Neste sentido, o resultado aponta que o SCFV, no município de Itaguaí, deve continuar oferecendo suas atividades, apesar de todos os seus problemas, sendo uma instância do Estado presente em territórios carentes de políticas públicas, buscando resolver suas dificuldades, pautando sua proposta de trabalho na ação conjunta entre o profissional pedagógico das unidades e os usuários dos territórios atendidos.

Em resumo, não cabem mais, em um Estado democrático, políticas públicas que tratem seus beneficiados como meros clientes, como se o Estado Ihes oferecesse favores. Devem-se ter como ideal, políticas públicas e sociais baseadas na construção, na execução e na avaliação de forma conjunta e dialógica com a sociedade civil, respeitando as particularidades endógenas de cada território, tendo como aspecto principal a promoção de ações práticas, que visem ao desenvolvimento das regiões atendias por essas políticas públicas.

\section{Referências}

BRASIL. Lei Orgânica da Assistência Social - LOAS. Lei Federal n 8.742, 7 de dezembro de 1993.

. Orientações técnicas sobre o serviço de convivência e fortalecimento e vínculos para crianças e adolescentes de 6 a 15 anos: prioridade para crianças e adolescentes integrantes do programa de erradicação do trabalho infantil. Brasília, 2010.

. Traçado Metodológico. Brasília, 2009.

CANÇADO, Airton Cardoso; PEREIRA, José Roberto; TENÓRIO, Fernando Guilherme. Gestão social: epistemologia de um paradigma. Curitiba: CRV, 2013

COSTA, Antônio Carlos Gomes. Protagonismo Juvenil: adolescência, educação e participação democrática. Salvador: Fundação Odebrecht, 2000.

FREIRE, Paulo. Pedagogia do Oprimido. 42. ed. Rio de Janeiro: Paz e Terra, 2005.

FUNDREM. Notas sobre Itaguaí e a baia de Sepetiba. Rio de Janeiro: 1976.

Secretaria de Planejamento e coordenação geral da governadoria do Estado do Rio de Janeiro. Itaguaí/RJ (relatório), 1981. 
GUEST, Greg; BUNCE, Arwen; JOHNSON, Laura. Quantas entrevistas são suficientes: uma experiência com a saturação dos dados e variabilidade. Field Methods: Sage, 2006

HAGUETTE, Teresa Maria Frota. Metodologias qualitativas na Sociologia. 5. ed. Petrópolis: Vozes, 1997.

IBGE. Instituto Brasileiro de Geografia e Estatística. Tabela População por Município. 2013. Disponível em <http://www.ibge.gov.br/home/estatistica/ populacao/ censo2010/tabelas_pdf/total_populacao_rio_de_janeiro>. Acesso em: 17 maio 2016.

ITAGUAÍ. Lei 3.204 de 23 de dezembro de 2013. Estabelece o abairroamento do município de Itaguaí, 16 jan. 2014.

LISBOA, Marijane. Ética e cidadania planetária na era tecnológica: O caso da proibição da Basiléia. Rio de Janeiro: Civilização Brasileira. 2009.

MACEDO, Lucimar Ferraz. Atuação dos conselhos comunitários no acompanhamento e participação cidadã no plano diretor de desenvolvimento sustentável do município de Itaguaí/RJ. 2013. 178f. Dissertação (Mestrado em Políticas Públicas) - Programa de Pós-Graduação em Desenvolvimento Territorial e Políticas Públicas, Universidade Federal Rural do Rio de Janeiro, Seropédica, 2014.

MANNHEIM, Karl. Diagnóstico de nosso tempo. Rio de Janeiro: Zahar. 1973

MDS. Concepção e Convivência de fortalecimento de vínculos. Brasília, 2013a.

. Desafio da Gestão do SUAS: Sistema Único de Assistência Social no municípios e estados. Brasília. Caderno 3, n. 3, ano 2, mar. 2007b.

. Reordenamento do Serviço de Convivência e Fortalecimento de Vínculos. Brasília, 2013b.

. SUAS: Configurando os eixos da mudança. Brasília, Caderno 2, n. 2, ano 2, mar. 2007a.

Tipificação Nacional. Brasília, 2014.

NOGUEIRA, Marcos Aurélio. Um Estado para a sociedade civil - Temas éticos e políticos da gestão democrática, São Paulo: Cortez, 2004.

RAMOS, Alberto Guerreiro. A nova ciência das organizações: uma reconceituação da riqueza das nações. Rio de Janeiro: Fundação Getúlio Vargas, 1989.

RUA, Maria das Graças; ROMANINI, Roberta. A implementação de políticas públicas. Instituto de Gestão em Economia e Políticas Públicas - IGEPP. Brasília, Unidade IX, 2014a.

; Feudalismo e Descentralização das políticas públicas no Brasil:

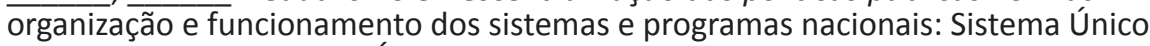
de Saúde (SUS) e Sistema Único da Assistência Social (SUAS). Instituto de Gestão em Economia e Políticas Públicas - IGEPP. Brasília, Unidade XI, 2014 b. 
SILVA, P. L. B.; MELO, M. A. B. O processo de implementação de políticas públicas no Brasil: características e determinantes de avaliação de programas e políticas. Cadernos de Pesquisa, n. 48, Unicamp, p. 1-17, 2000.

SIRAQUE, Vanderlei. Controle Social da função administrativa do Estado: possibilidades e limites na constituição de 1988. 2. ed. São Paulo: Saraiva, 2009.

SOUZA, C. Políticas Públicas: uma revisão da literatura. Sociologias, Porto Alegre, ano 8, n. 16, p. 20-45, jul. dez. 2005.

TENÓRIO, Fernando Guilherme (Org.). Cidadania e desenvolvimento local: Critérios e análises. Rio de Jairo: FGV, 2012.

(Org.). Gestão Social e gestão estratégica. Rio de Janeiro: FGV, 2013.

THIRY-CHERQUES, Hermano Roberto. Saturação em pesquisa qualitativa: Estimativa Empírica do Questionamento. Revista PMKT, São Paulo, ano 2. v. 3, p. 20-27, set. 2009.

VERGARA, Sylvia Constant. Projetos e relatórios de pesquisa em administração. 9. ed. São Paulo: Atlas, 2007

WEBER, Max. A ética protestante e o espírito do capitalismo. São Paulo: Ática, 1979. (Coleção os Pensadores). 